\title{
MAX GLÜCKSMANN: SUS PRIMEROS PASOS EN LA "CASA LAPAGE". DESCUBRIENDO AL PIONERO DEL CINEMATÓGRAFO
}

\section{MAX GLÜCKSMANN: SEUS PRIMEIROS PASSOS NA "CASA LAPAGE". DESCOBRINDO O PIONEIRO DO CINEMA.}

\author{
MAX GLUCKSMANN: HIS FIRST STEPS IN THE "HAUSE \\ LAPAGE". DISCOVERING THE PIONEER OF THE CINEMA
}

Gabriela Ximena Gómez ${ }^{1}$

\section{RESUMEN}

Este artículo forma parte de un trabajo más amplio en el marco de un proyecto de investigación. Este espacio se ocupa de las industrias culturales en la ciudad de Buenos Aires entre el inicio del siglo XX y el final de entreguerras. En ese contexto, lo que me interesa es observar el recorrido de un pionero de la industria del espectáculo, fotógrafo, director, productor, distribuidor, etc., el empresario austríaco Max Glücksmann. Junto a la transformación que vivió la ciudad de Buenos Aires desde finales del siglo XIX y principios del XX, y a las transformaciones en la técnica, aparecieron inmigrantes, intuitivos, emprendedores y que buscando un rédito comercial irían construyendo el mercado de entretenimientos de la Argentina.El presente trabajo intentará dar cuenta de los primeros pasos de Glücksmann, uno de estos inmigrantes, como empleado de la Casa de fotografía Lapage que se encontraba en el centro de la ciudad de Buenos Aires, para luego pasar a ser su gerente y culminar como dueño de la misma. Y transformarse desde este espacio con el correr del siglo $\mathrm{XX}$ en uno de los hacedores de la cinematografía y de la industria del disco en la Argentina. Para esto haremos un recorrido por fuentes gráficas de la época intentando realizar una reconstrucción del entramado del circuito cultural por donde se desenvolvía. Como también, observar el crecimiento de la ciudad, los habitantes que empiezan a circular y que aparecen como posibles consumidores de diferentes productos. A partir de la observación de los métodos de comercialización, como por ejemplo la publicidad, y del análisis de cómo estaba organizada la Casa Lapage distinguiremos el accionar de Max Glücksmann como gerente del comercio y miraremos el itinerario sobre las decisiones que tomaba y como ayudaron a delinear el naciente mercado de entretenimiento de la ciudad de Buenos Aires.

Palabras claves: Cine. Pioneros. Mercado de Entretenimiento. Mercado de Consumo. Publicidad.

\footnotetext{
${ }^{1}$ Universidad Nacional Arturo Jaretche/Universidad Nacional de Buenos Aires (Argentina). E-mail: gaxigomez@gmail.com
} 


\section{RESUMO}

Este artigo é parte de um trabalho mais amplo no marco de um projeto de pesquisa. Este espaço se ocupa das indústrias culturais da cidade de Buenos Aires entre o início do século XX e o final do Entre-Guerras. Nesse contexto, o que me interessa é observar o percurso de um pioneiro da indústria de espetáculo, fotógrafo, diretor, produtor, distribuidor, etc., o empresário austríaco Max Glücksmann. Junto à transformação que viveu a cidade de Buenos Aires desde o final do século XIX e princípio do século XX e às mudanças na técnica, apareceram imigrantes intuitivos, empreendedores e que buscando um retorno comercial construíram o mercado de entretenimentos da Argentina. O presente trabalho tentará dar conta dos primeiros passos de Glücksmann, um destes imigrantes, como empregado da Casa de Fotografia Lapage, que se encontrava no centro da cidade de Buenos Aires, para logo passar a ser seu gerente e culminar como dono da mesma. E a partir deste espaço, com o decorrer do século XX, transformar-se em um dos criadores da cinematografia e da indústria do disco na Argentina. Para isso, faremos um percurso por fontes gráficas da época tentando realizar uma reconstrução do circuito cultural por onde se desenvolvia. Como também, observar o crescimento da cidade, os habitantes que começam a circular e que aparecem como possíveis consumidores de diferentes produtos. A partir da observação dos métodos de comercialização, como por exemplo, a publicidade, e das análises de como estava organizada a Casa Lapage, identificaremos como Max Glüscksmann torna-se gerente do comércio e olharemos o itinerário das decisões que tomava e como ajudaram a delinear o nascente mercado de entretenimento da cidade de Buenos Aires.

Palavras-chave: Cinema. Pioneros. Mercado de Entretenimento. Mercado de Consumo. Publicidade. 


\begin{abstract}
This article is part of the results of research project. We investigated the Buenos Aires city's cultural industries from the early twentieth century and the end of the begin of War World Second. In this context, my interest is to observe path of a pioneer of show industry, photographer, director, producer, distributor, etc., the busissman Austrian Max Glücksmann. Along the transformation that lived the city of Buenos Aires since the late nineteenth century and beginning of the twentieth century and changes the technique appeared intuitive immigrants, busissman and seeking a commercial return built the entertainment market in Argentina. This paper attempts to give keep up with the first steps of Glücksmann, an immigrant such as employee Lapage Photography house that was in the center of Buenos Aires, soon pasar to be his manager and culminate as the owner of it. And from this space, in the course of the twentieth century to become one of the entrepreneurs of the cinematography and the record industry in Argentina. For this, we will use of graphic sources of the time trying to make a reconstruction of the cultural circuit where developed. As also noted the growth of the city, the locals begin to circulate and appearing as potential consumers of different products. From the observation of the marketing methods such as advertising, and analyzes of how was organized the House Lapage, identify as Max Glüscksmann becomes manager of trade and look at the itinerary of decisiones he took and how they helped to shape the entertainment market of the city of Buenos Aires.
\end{abstract}

Keywords: Movie Theater. Pioneers. Entertainment Market. Consumer Market. Publicity. 


\section{A modo de presentación}

Esta publicación forma parte de un trabajo más amplio en el marco de un proyecto de investigación que se ocupa de las industrias culturales en la ciudad de Buenos Aires entre el inicio del siglo XX y el final de entreguerras. En ese contexto me interesa mostrar el recorrido de un pionero de la industria del espectáculo que se convirtió con el correr del tiempo en productor, distribuidor y dueño de varios locales de exhibición cinematográficos, así como también en un importante empresario en el mundo de la discografía, el austríaco Max Glücksmann.

En el presente artículo trabajaré sobre los primeros años de Glücksmann en la Casa Lapage, entre 1895 y 1908, este comercio lo tuvo primero como empleado, luego como gerente, para culminar como dueño del mismo y desde ahí construir lo que sería la empresa Max Glücksmann. Este negocio fue uno de los primeros en la Buenos Aires de finales del siglo XIX en ofrecer todo lo necesario para el fotógrafo, para su trabajo, la casa además se ocupaba de retratar a la sociedad porteña. Fue una de las primeras en utilizar estrategias de comercialización, publicidad, para acercarse a un potencial comprador, consumidor de esta nueva tecnología, "la fotografía". Este comercio que, con el correr de los años

y con el inicio del siglo $\mathrm{XX}$, ira sumando otros servicios que irán creciendo con el pasar de los años y de las mejoras técnicas.

La observación de los circuitos y el funcionamiento de la Casa Lapage nos ayuda a rastrear el recorrido de Max Glücksmann, que fue uno de los primeros emprendedores, pioneros en estos nuevos artes, que combinó: los avances técnicos, con las imágenes, con el surgimiento de nuevos lenguajes. A partir de este nuevo escenario y de cómo lo observamos en la prensa, se nos presentan algunas preguntas básicas sobre el funcionamiento de este novedoso negocio urbano, ¿qué se encuentra detrás de lo observable?, ¿hay un público que consume estos productos?, ¿de qué productos estamos hablando?, ¿cuál es la circulación de ellos?, ¿están a la mano de una cantidad de personas más amplia que los sectores de la elite?, ¿de qué nos hablan las publicidades?, y estas cuestiones también nos ayudarán a reflexionar sobre la forma de conducirse por el gerente de este comercio, cómo piensa ese mercado que se abre. 
En este primer momento nos limitaremos a revisar una fuente en particular, la revista Caras y Caretas. Lo haremos en determinados años: 1899, 1900, 1901, 1905, para indagar posibles cambios en las ofertas y en los productos ofrecidos. La temporalidad elegida es en función de la primera proyección cinematográfica en Buenos Aires realizada en 1896 y del $1^{\circ}$ corto filmado en la Argentina en 1897. Dicha búsqueda con esta temporalidad nos interesa para poder observar la forma de conducirse de Glücksmann como gerente de este comercio, qué relaciones fue forjando, cómo se orienta en el naciente negocio del cine y como irá sumando al mercado de entretenimiento que se estaba organizando su impronta, sus ideas.

\section{Para comenzar. Un poco de historia sobre los orígenes del cine y sus protagonistas.}

El fenómeno del cine o las "vistas animadas" cómo se las llamó al comienzo, tuvieron su origen de la mano de los hermanos Lumiére en Francia. La primera proyección se realizó el 28 de diciembre de 1895 en París teniendo un gran éxito, a partir de esta exhibición la distribución del producto se extendió por gran parte de Europa y también por distintos países de América Latina como fue el caso argentino, el chileno y el mexicano (CUARTEROLO, 2014).

A menos de un año de su estreno en Francia, la prensa porteña, nos contaba de la proyección de las "vistas" animadas. A sí para el 18 de julio de 1896, en el Teatro Odeón, se exhibió por primera vez una película. Ya para el 20 de julio el diario La Prensa dio cuenta de este suceso. En los primeros párrafos de la noticia nos informaba sobre la obra de teatro que se está representando, el drama "A orillas del mar" de D. José Echegaray. En el cuarto párrafo se leía: “Otra novedad, aunque de distinto género, es la que ofrece desde ayer el Odeón, a la pieza correspondiente a cada sección sigue la expresión de un cierto número de vistas del cinematógrafo: con lo que se hará popular este curioso invento2". En esta primera vista se exhibió "La llegada del Tren a la estación" de los hermanos Lumiére.

2 Diario La Prensa, fecha 20 de julio de 1896, la referencia esta sacada de la página 6 de la sección Boletín del día, Novedades Teatrales. 
En una de estas primeras funciones, el 27 de julio de 1896, estuvieron presentes el Barón belga Henry Lapage, con los empleados de su comercio, Max Glücksmann y Eugenio Py (MARRONE, 2003). Un contemporáneo no se podría imaginar lo que estaba sucediendo en ese momento, pero allí estaba naciendo la cinematografía en la Argentina. Cuánta razón tenía el diario que anticipaba unos días antes "se hará popular este curioso invento". Ambos empleados fueron pioneros en este nuevo período y en estos nuevos emprendimientos, el francés sería uno de los primeros "tomavistas"3, como se hacían llamar estos personajes, mientras que Glücksmann se fue transformando en "un prolífico productor de cortos de noticias y distribuidor de películas" (KARUSH, 2013, p.71).

\subsection{La ciudad de Buenos Aires y el Cine}

El mercado de Buenos Aires era un espacio muy fructífero para este nuevo arte, tanto si se observan la cantidad de espectadores dispuestos y expectantes en este nuevo entretenimiento, como si miramos la cantidad de realizadores que irán apareciendo. Para 1906 podemos hablar de 133.740 espectadores y un año más tarde se podía observar que este número había crecido a 666.370. Si comparamos estos números con los del mundo del teatro popular, el llamado de "género chico", que para ese año de 1907 vendió para la zarzuela 1.050.3604 de entradas, el mercado del cine se encontraba en formación, pero en crecimiento sostenido como se irá comprobando.

Los datos sobe las entradas vendidas nos hablan de un Buenos Aires que para ese entonces era una ciudad en transición, abandonando sus características de gran aldea para transformarse en una ciudad moderna. Esto se reflejó en su arquitectura, en su organización urbana, en la cantidad de población, en los espacios de sociabilidad. Por ejemplo, la cantidad de población se cuadriplico en el lapso aproximado de 40 años, el primer censo nacional realizado en 1869 arroja la cifra de 1.877 .490 habitantes y en el tercer censo de 1914 el país contaba con 7.903 .662 habitantes.

3 A Eugenio Py se le atribuye el primer "corto" filmado en la Argentina "La Bandera Argentina" de 1897.

4 Datos extraídos de Cinema Halls in Buenos Aires a XX century Heritge. 
Los transportes también daban cuenta de esta transformación del caballo y el carruaje a tranvías a tracción a sangre en 1870 para irse modificándose a eléctrico hacia 1897. Esto favorecía la movilidad de la población de las áreas más lejanas al centro de la ciudad que para mediados de la década del 10 ya habían ocupado espacios como la zona del Abasto y otras. Además de contar para este momento con ferrocarriles que acercaban al centro urbano de Buenos Aires con el interior del país y con las zonas que circundaban a la ciudad (BARSKY y BARSKY, 2008).

En esta ciudad en continuo cambio el mercado del cine encontró espacio para desarrollarse, eso lo vemos con los anuncios de los diarios en sus secciones de espectáculos donde se hablaba de las exhibiciones de las "vistas animadas" las cuales eran habituales y pasaban a ser parte de distintos espectáculos como otra atracción más y se podían ver en teatros, circos, cafés o restaurantes. Recién para 1900 se inauguró el primer cinematógrafo, el mismo se organizó en una pequeña sala de una casa de familia adaptada para este uso. Esta primera sala en un principio tenía capacidad para una docenas de personas, el cual estaba ubicado en Maipú 471/79 entre Lavalle y Corrientes era el Salón Nacional, ya para 1914 el tercer censo nacional nos muestra que en la ciudad de Buenos Aires funcionan 98 salas de cines.

\subsection{Max Glücksmann}

Las primeras vistas eran filmaciones de un par de minutos de duración donde se mostraban distintos paisajes y personajes. Luego hacia el final de la primera década del siglo XX aparecieron las primeras cintas argumentales extranjeras, primero europeas y luego norteamericanas. Esta primera etapa del cine fue de una precariedad absoluta, pero de mucha exploración e imaginación. Estos primeros hombres que registraron imágenes y que contaron historias desde la película se autodenominaron "tomavistas" porque experimentaban una gran fascinación al poder atrapar un instante de realidad en la película de cine.

En esta primera evolución del cinematógrafo que tuvo mucho de películas extranjeras, también fue acompañada por la construcción de un cine nacional. Primero con vistas y luego con cintas argumentales. Pero esta construcción se realizó en base al trabajo de inmigrantes 
autodidactas que llegaban con mucho entusiasmo, ningún capital, un gran espíritu emprendedor y mucha intuición.

Este fue el caso de Max Glücksmann quien fue un judío austríaco que llegó a la Argentina en 1890 con quince años. A poco de su llegada consiguió trabajo como sereno en una fábrica, el cual le duró poco. Fue entonces que conoció y entró a trabajar como cadete para el barón Lapage, en la "Casa Lapage", que era "el faro para los fotógrafos porteños" (FERNANDEZ RUSSO, 2008). Lapage era uno de los fotógrafos que retrataba a la sociedad porteña, además de tener en su negocio el mejor surtido para el fotógrafo en la ciudad.

FIGURA 1 - Un joven Max Glücksmann

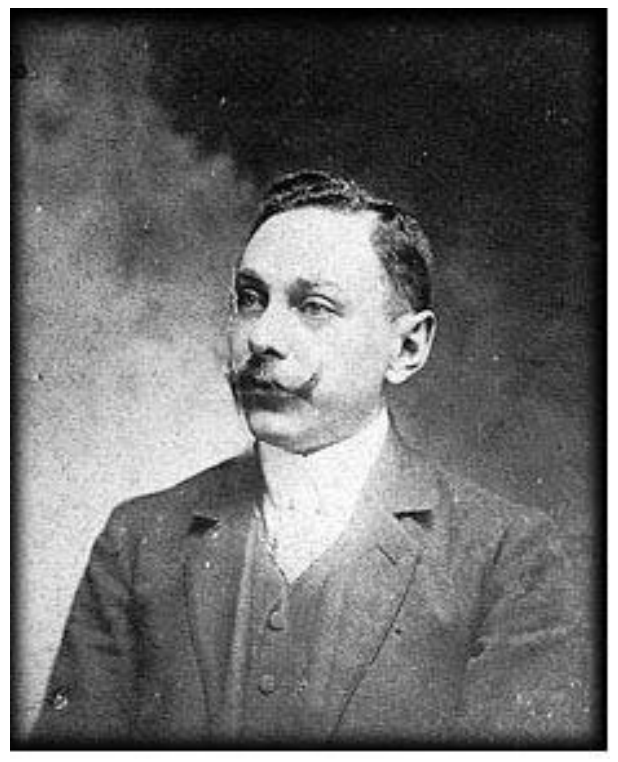

Glücksmann, al igual que la ciudad de Buenos Aires, se encontraba receptivo a todas las novedades técnicas a nivel mundial. Como ya se mencionó anteriormente, el fue uno de los primeros espectadores las vistas animadas exhibidas en la ciudad, para ese entonces 1896, ya no era el cadete de la Casa Lapage, sino su joven Gerente. Como tal tuvo la gran intuición que ese nuevo entretenimiento era el futuro y no se equivoco. A partir de eso trabajo para traer el cine primero a la Argentina y luego al Cono Sur. 
Los Lumiére comenzaron el negocio del cine con la exhibición, pero a esto le siguió la patentación de los aparatos para filmar las películas, la venta de las cámaras para filmar, así como también las máquinas que servían para proyectar las cintas. Glücksmann, vio la oportunidad de comerciar estos aparatos y entonces viajo a Francia a traer el cine de los Lumiére a Buenos Aries, pero este contacto comercial no se realizo. Entonces estando en Francia se contactó con Gaumount y también con Pathé, a partir de ese encuentro se consolido un vínculo comercial que lo llevó a transformarse en el representante para los países de América del Sur de ambos. (FERNANDEZ RUSSO, 2008).

Los primeros creadores realizaron desde breves noticieros, hasta documentales elementales. En octubre de 1900 el médico Pedro Arata, fotógrafo aficionado filmó "El arribo del presidente de los Estados Unidos del Brasil Doctor Campo Salles al puerto de Buenos Aires" donde se mostraba la llegada al puerto del presidente electo del Brasil junto al presidente argentino Julio A. Roca y se sumaba la presencia de Bartolomé Mitre5. En 1902 en un programa del "Gran Biógrafo y Variedades Salón París" ubicado en la calle Cangallo, anunciaba "Vistas de Mar del Plata", "Grupos de familias distinguidas", "La vida social en el Bristol Hotel”, etc. (TRONCOSO, 1971, p. 44). Hubo que esperar hasta 1909 para que apareciera la primera película argumental "La Revolución de Mayo" dirigida por Mario Gallo y al mismo director le debemos también "La batalla de Maipú", "Camila O’Gorman” y "El fusilamiento de Dorrego". Glücksmann fue uno de ellos, ya en los avisos de los diarios de los primeros años del siglo XX o en las carteleras de los cines se podían leer los anuncios "Variedades Max Glücksmann" o "Actualidades Max Glücksmann" (MARRONE, 2003, p.30).

En los años 10 se producen exhibiciones mixtas de filmaciones de eventos sociales o noticias de la ciudad con películas documentales. Para los primeros films argumentales nacionales hubo que esperar hasta la época del Centenario de Mayo, pero hacia 1907 Glücksmann importó las primeras películas con banda sonora desde Europa. Entonces nuestro personaje desde su posición en la "Casa Lapage" se había convertido el "factótum comercial” (PUJOL, 1994, p. 64) del cine en Buenos Aires

5 Con este "corto" se inició una serie de realizaciones de que tienen a los miembros más distinguidos de la sociedad argentina entre los cinematografiados. Entre las cintas se pueden encontrar: Mitre visita las instalaciones del nuevo edificio del Museo Histórico Nacional emplazado en Parque Lezama, El presidente Roque Sáenz Peña visita Tucumán por el $96^{\circ}$ aniversario del 9 de julio. Marrone, Irene (2003). 
porque era productor de actualidades, además de comprador y distribuidor de películas extranjeras en nuestro país y en los vecinos.

Esto era posible entre otros motivos porque era el concesionario de Pathé Frères de París, ya mencionado más arriba, pero esto también le garantizo que estas "Actualidades" o "Variedades Max Glücksmann" fueran exhibidas en Europa6. Es decir, la relación con el viejo continente no solo le sirvió para nutrir su negocio7 de cintas para distribuir, sino también que logró que distribuyeran sus vistas en los salones cinematográficos del otro continente.

FIGURA 2 - Max Glücksmann en su oficina

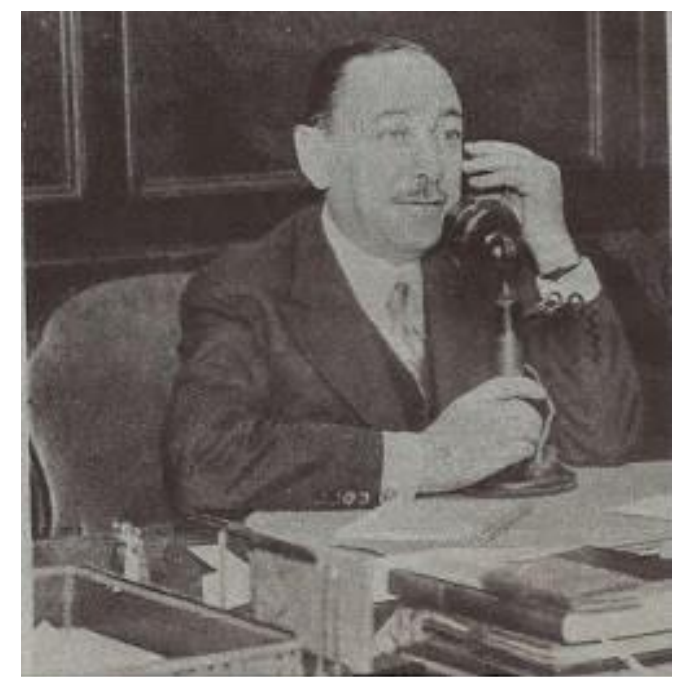

Max Glücksmann, que industrializó la fotografia y la fonografia en el pai, figura también entre los primeros exhibidores y productores cinematográficos del Plata.

Esto fue el inicio de una trayectoria mucho más amplia, que incluye ser uno de los empresarios más importante del mundo discográfico, y ser uno de los pioneros de la construcción de la cultura de masa en la Argentina. Pero esto sucedió a partir de la organización y funcionamiento de la "Casa Lapage" de la cual me quiero ocupar en este

6 Caras y Caretas, 27 de febrero de 1909, №544, p. 12.

7 Max Glücksmann le compró “Casa Lapage” al barón Henri Lapage en 1908 pues este debió regresar a Europa por razones de salud de su esposa. 
momento en función de poder observar cómo era ese incipiente mercado de entretenimiento de Buenos en la primera década de 1900.

\section{La Casa Lapage}

La casa Lapage era un comercio donde se vendían cámaras de fotografía y todo tipo de productos relacionados con este arte. Estaba ubicada en pleno centro de la ciudad, en la calle Bolívar 375, y era un lugar de referencia para todo aquel que estuviera interesado en estos nuevos productos. Llegó a tener múltiples sucursales, en capital, en el interior de la Argentina en ciudades como Rosario y Mendoza; y el exterior en países como Uruguay y Chile.

En estos primeros años del siglo XX además de la casa central contó con una sucursal que fue modificando su dirección, pero siempre en pleno centro de Buenos Aires. De allí seguramente el interés de los protagonistas por ser parte de esta nueva industria, el cine, que estaba relacionada con la fotografía.

Luego de la primera proyección cinematográfica la Casa Lapage se interesó en este nuevo invento y comenzó a comercializar filmadores marca Gaumount y proyectores, las primeras cámaras llegaron al país en el año 1897. Pero lo que quedaba claro era que todavía el funcionamiento del comercio se centraba en los otros productos.

La especificidad del negocio hace interesante rastrear cuáles eran las estrategias de comercialización del mismo, puesto que esta metodología era nueva para este momento y va acompañando la formación de un mercado de consumo (ROCCHI, 1999). La dinámica iba dirigida en captar al consumidor inadvertido, que para el tipo de productos de Casa Lapage, estaba contenido entre la elite y las nacientes clases medias. Las características de la comercialización estaban relacionadas con el uso de la marca, el uso del crédito y con los avances de la publicidad. Todo esto iba atado además a individuos que se empezaron a observar que había que realizar una apelación a los sujetos para atraparlos y transfórmalos en consumidores. Los artífices de estas situaciones son aquellos hombres con una mentalidad abierta y dispuestos a apelar a instrumentos nuevos para hacer crecer sus negocios como es el caso de Glücksmann con la Casa Lapage. 
La primera y fundamental estas estrategias fue la instalación del propio comercio y la difusión entre los habitantes de sus productos como las placas para las cámaras fotográficas, cartones de soporte, álbumes, modelos de galería de pose o de representación de imágenes, además de contar con un estudio para realizar lo que hoy llamaríamos sesiones fotográficas. Es decir la instalación de la Casa Lapage como marca relacionada con las nuevas técnicas.

También el comercio ofreció fonógrafos y gramófonos, con los consiguientes cilindros y discos para ser escuchados en estos aparatos. Para los cilindros y discos ofrecían "pasen por nuestro negocio para poder revisar nuestro importante catálogo que se actualiza continuamente" o "nuestro catálogo ilustrado" está disponible para todo aquel que lo solicite. Además de esto, también había un catálogo ofrecido a los negocios del interior del país a quienes a su vez también nutrían de materiales y productos funcionando como intermediarios.

Sumado a lo anterior, la Casa Lapage fue una de las primeras en utilizar otra estrategia de comercialización como lo fue la publicidad en los medios gráficos.

\section{La estrategia de la publicidad, la apuesta por la innovación}

Los cambios que se operaban en la ciudad de Buenos Aires para la década del 10 llevaron a la ampliación del mercado en todo el sentido de la palabra, o podríamos decir a la creación de uno. En referencia al tema que nos interesa esto significó que la imagen dejo de estar sujeta al retrato de las elites en el estudio del fotógrafo para compartir la escena con la aparición de el fotógrafo amateur y de la fotografía costumbrista, la cual fue la base del reportero gráfico contemporáneo.

También fue cierto que para esta transformación se produjera la técnica tuvo que avanzar y la aparición de la cámara portátil fue fundamental, la misma tenía un funcionamiento sencillo, era pequeña y a esto se sumaba también el servicio de revelado y copias realizado por profesionales (PRIAMO, 1999).

A través de la observación de las publicidades de la "Casa Lapage" de la revista "Caras y Caretas" y también mirando la de otros comercios 
relacionados con este rubro buscaremos dar algunas respuestas a este mercado en crecimiento o en formación. Esto nos parece significativo ya que fue a partir de la publicidad qué podremos observar cómo pensaba, en este caso Max Glücksmann, la apelación a este consumidor, ya sea un propietario de un establecimiento de entretenimientos, como al hombre que trabaja en una oficina.

La revista "Caras y Caretas" inició su circulación en la ciudad de Buenos Aires en el año 1898, con una tirada inicial de 15.000 ejemplares, una veintena de páginas y unas cuantas publicidades de algunos productos. Para 1905 contar con una tirada de 84.700 ejemplares, unas cuantas páginas más y muchas propagandas en su haber.

Esto es significante para observar cómo va creciendo y ampliándose los diferentes espacios dedicados a la publicidad dentro de la publicación en el transcurso de los años. Esto nos importa para poder evaluar cómo va cambiando o mejor dicho se fue gestando el mercado de consumo. Esto también nos marca como va creciendo la ciudad, los habitantes que empiezan a circular y que aparecen como posibles consumidores de diferentes productos. En este sentido la estrategia que mostró Casa Lapage era apelar a ese mercado que se mostraba segmentado desde los recursos económicos, desde aquí se puede inferir que quién dirigía los destinos del comercio, Glücksmann, planteo diferentes discursos y diferentes precios para ampliar su clientela.

La revista tenía una amplia gama de productos a los cuales les ofrecía sus páginas para ser promocionados. Allí se encontraban manufacturas importados hasta los de origen nacional. Compartían el espacio las mercancías de metal como la máquina de coser con el arado para las tareas del campo. De los productos lácteos para toda la familia a las ofertas de indumentaria como los sombreros, los trajes, y sobretodos para los caballeros, los vestidos y tapados para las damas, y los trajecitos para los niños. Apareciendo también la oferta de ropa de trabajo. Pasando por los velocípedos, bicicletas, muebles de madera como escritorios, bibliotecas y todo tipos de mesitas. Y por supuesto todo tipo de productos como cigarrillos, licores, galletitas, chocolates, cerveza, relojes, joyería y los servicios de los dentistas. Además de los tónicos que servían para reparar cualquier tipo de dolores o malestares gástricos, reumáticos, intestinales, etc., todo esto acompañado de productos embellecedores y de limpieza. 
La Casa Lapage según los momentos ofrecía un anuncio de un cuarto o de media o a veces a página completa. Estos últimos casos no era lo habitual. Para la época de final de año siempre había ofertas y a veces se interpelaba al comprador para que aproveche el "aguinaldo". Otra característica era que tenía épocas que anunciaba todas las semanas y luego pasaba a poner un aviso una vez al mes.

En el primer año de la publicación ya encontramos pequeños avisos de la Casa Lapage, el primero es del 26 de noviembre de 1898, y lo que trataba de publicitar era la aparición del "nuevo Catálogo Ilustrado, de APARATOS Y UTILES FOTOGRAFICOS, se manda gratis"8. Claramente en este registro trataba de institucionalizar el formato de catálogo para acceder a los diferentes artefactos y productos que la casa vendía. Y a la vez pensaba su gerente como poder hacer llegar sus productos a otros lugares más allá de la ciudad de Buenos Aires.

\section{FIGURA 03 - Publicidad "Casa Lapage”}

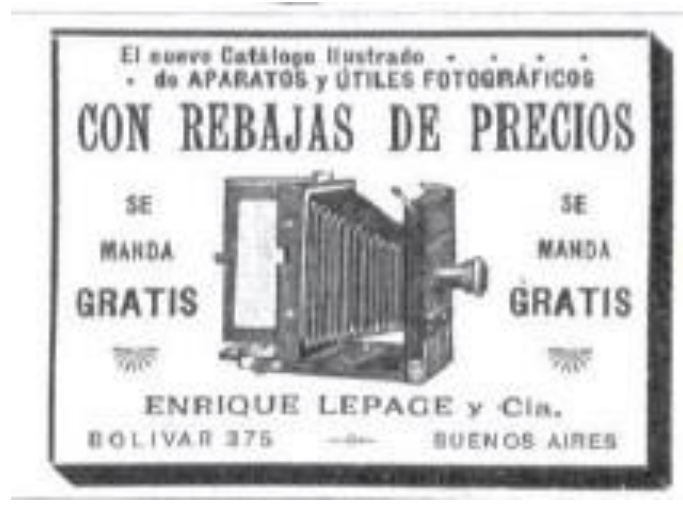

Fonte: revista Caras y Caretas, N 8, 26 de febrero de 1898

El año siguiente las promociones que llevó adelante el comercio incluyeron otros productos, además de los relacionados con la fotografía, apareció por primera vez la frase el "Teatro en casa con los nuevos grafófonos que canta y hablan en alta voz y reproducen los

8 Caras y Caretas, № 8, 26 de noviembre de 1898. 
sonido"9. Cada vez que los aviso llevaban ese título lo que ofrecían se vinculaba con aparatos que se utilizaban para la reproducción del sonido. Esto se completaba con el ofrecimiento del catálogo, y el precio en que estaba valuado el producto, $\$ 55$ moneda/nacional10. A lo largo de 1899 mantuvo este tipo de promociones, pero lo llamativo fue que el precio de los productos fue bajando y para agosto de ese año estaba en $\$ 20 \mathrm{~m} / \mathrm{n}$.

Algo interesante para este momento fue lo que la competencia de la Casa Lapage mostraba en las publicidades. Son parecidas, pero cada una buscaba su estilo. Aun ninguna hablaba sobre una marca particular, como será en el futuro Edison, Pathé, Víctor, Kodak, etc., pero si cada una trataba de atraer al público para su comercio con apelaciones particulares. Así encontramos otras casas que también tienen productos relacionados con la fotografía, el sonido e incluso el cine, ellas eran Casa Guppy, Casa Gregorio Ortuño, Casa Cassels, Bazar Yankee, Casa Tagini.

Una de las características compartidas por estos comercios fue que en las publicidades hablaban de los productos que vendían, a veces promocionaban los productos que reproducían sonidos, a veces las cámaras de fotografía y los útiles necesarios para desarrollarla o a veces todos juntos, más otros artículos que tenían en sus negocios, como por ejemplo lámparas a baterías para bicicletas.

En el número 44 de la revista, agosto de 1899, apareció una publicidad de Casa Guppy que partía de una pregunta: ¿Qué es un gramófono? Y allí había una sucinta explicación técnica y se mostraba además que dispositivos se le podían sumar para sus distintas funcionalidades. Además de ofrecernos un cinematógrafo minúsculo o SKA un Kinetoscopio para la familia con 6 cintas al precio ínfimo de $\$ 18.11$

9 Caras y Caretas, $\mathrm{N}^{\circ}$ 21, 25 de febrero de 1899, p. 24.

10 En adelante $\mathrm{m} / \mathrm{n}$.

11 Caras y Caretas, № 44, 05 de agosto de 1899, p. 6. Publicidad de página completa. 
FIGURA 04 - Publicidad "Casa Lapage"

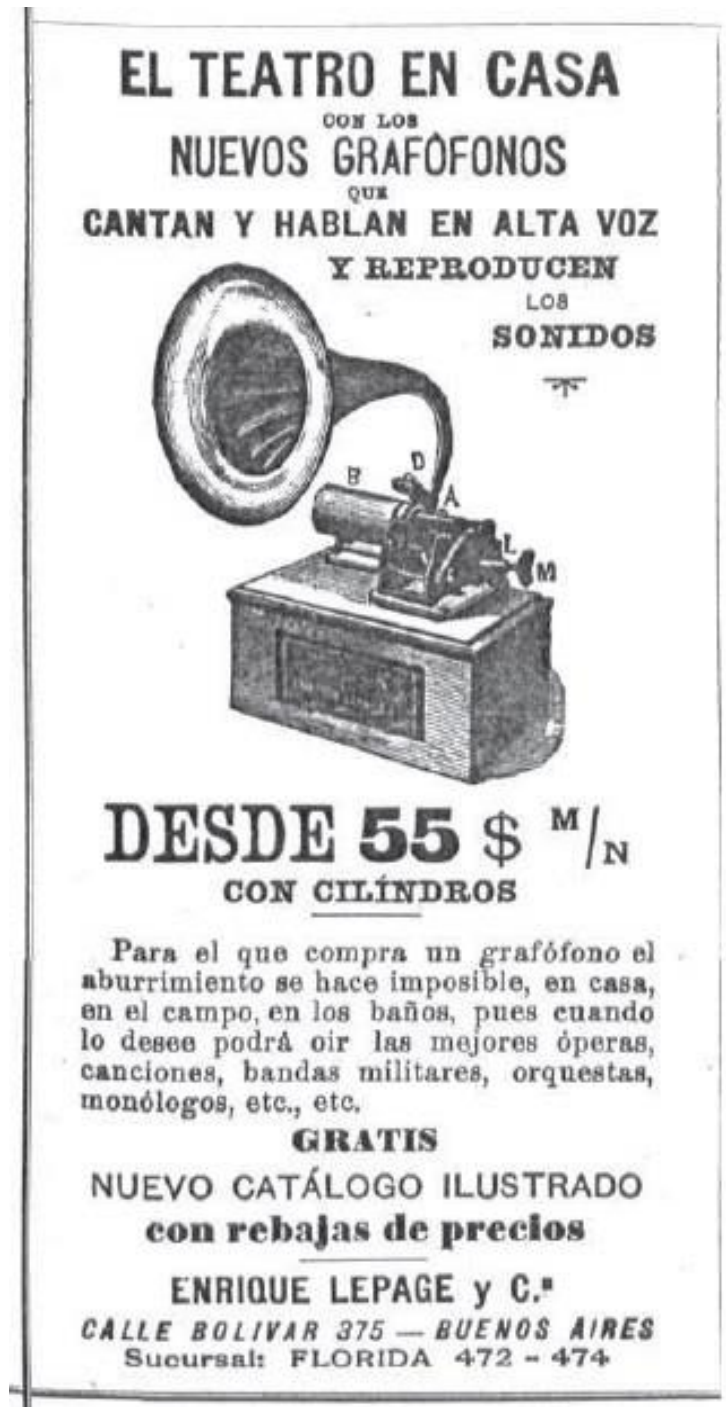

Fonte: Revista Caras y Caretas, N 21, 25 de febrero de 1899

En el número 65 apareció un aviso de la Casa Gregorio Ortuño que era un señor andando en bicicleta y esta arrastraba un carrito que tenía escrito "FOTOGRAFIA. Aparatos, Útiles, Drogas". Además de ofrecer un gran catálogo ilustrado. Es decir, el comercio salía a la calle y era como un vendedor ambulante. 12

12 Caras y Caretas, $\mathrm{N}^{\circ}$ 65, 30 de diciembre de 1899, p. 12. Publicidad de página completa. 
En el inicio del siglo XX Casa Lapage, siguió ofreciendo "El teatro en Casa", "cantan y hablan tan alto como la voz humana", reproducían discursos, conversaciones, canto y música. Tenían un surtido de más de 1500 cilindros, y se encontraba a disposición de quien lo solicitara gratis el gran catálogo ilustrado. A su vez la Casa Guppy recurría a un discurso similar, pero en su publicidad aparecía una pareja de adultos mayores escuchado el gramófono. Con esto apelaban al imaginario de que cualquiera estaba capacitado para operar los nuevos artefactos, estaban al alcance de todos.

La mayoría de los comercios también ofrecían con los aparatos cilindros vírgenes, para grabar, se vendían por docena. Y cilindros impresos con una importante variedad musical desde la Opera Italiana, la zarzuela, hasta el repertorio del Teatro Mayo. Más adelante aparecerán los discos planos, y con ellos los anuncios que a los clásicos musicales hasta ese momento se le sumaría el repertorio criollo hecho en París o Londres por artistas enviados especialmente a grabar allí, para esto último habrá que esperar hasta 1905.

Para 1900 algunas casas empezaban a explicitar con que marca trabajaban, así Casa Guppy nos informaba que sus productos eran de la fábrica de Edison. O la Casa Ortuño que las placas que vendían para sus cámaras eran Lumiére. Otra promoción del Bazar Yankee, luego de publicitar que contaban con todos los útiles y drogas para el arte de la fotografía, también nos aconsejaba que "Guárdense de los anuncios. ¡Pidan Catálogos!’13.

Para este momento la Casa Lapage también muestra todas sus cartas y, en un anuncio de fin de año, seguía con la promoción del "Teatro en Casa", y en el mismo anuncio también nos hablaba que contaba con todo para la fotografía, además de sumar un pequeño apartado "CINEMATÓGRAFO. ULTIMA NOVEDAD” donde ofrecía cinematógrafos para aficionados, para teatros y espectáculos públicos y "vistas" para Cinematógrafos y accesorios 14.

Aparecía el cinematógrafo para los aficionados, pero también había una clara alusión a otro usuario, aquel que tenía un teatro o tenía un espacio que brindaba algún tipo de espectáculo. Se le contaba que este comercio contaba con el equipamiento necesario para poder brindarle la "última 
novedad del cine". Además de avisarle que contaba con las películas "vistas" para que pudiera proyectarlas. Entonces a la venta, se suma la incipiente distribución de cintas que esta casa fue precursora.

Observando estos anuncios se puede inferir que Glücksmann, a partir de estas publicidades, fue construyendo todo un circuito de alquiler y prestamos de cintas para diferentes comercios relacionados con el mundo del espectáculo. Además de poner en el mercado la distribución de películas extranjeras, ya que era el concesionario de Pathé Frères de París, también difundía sus cortos de noticias producidas por él mismo.

FIGURA 5 - Publicidad "Casa Lapage"
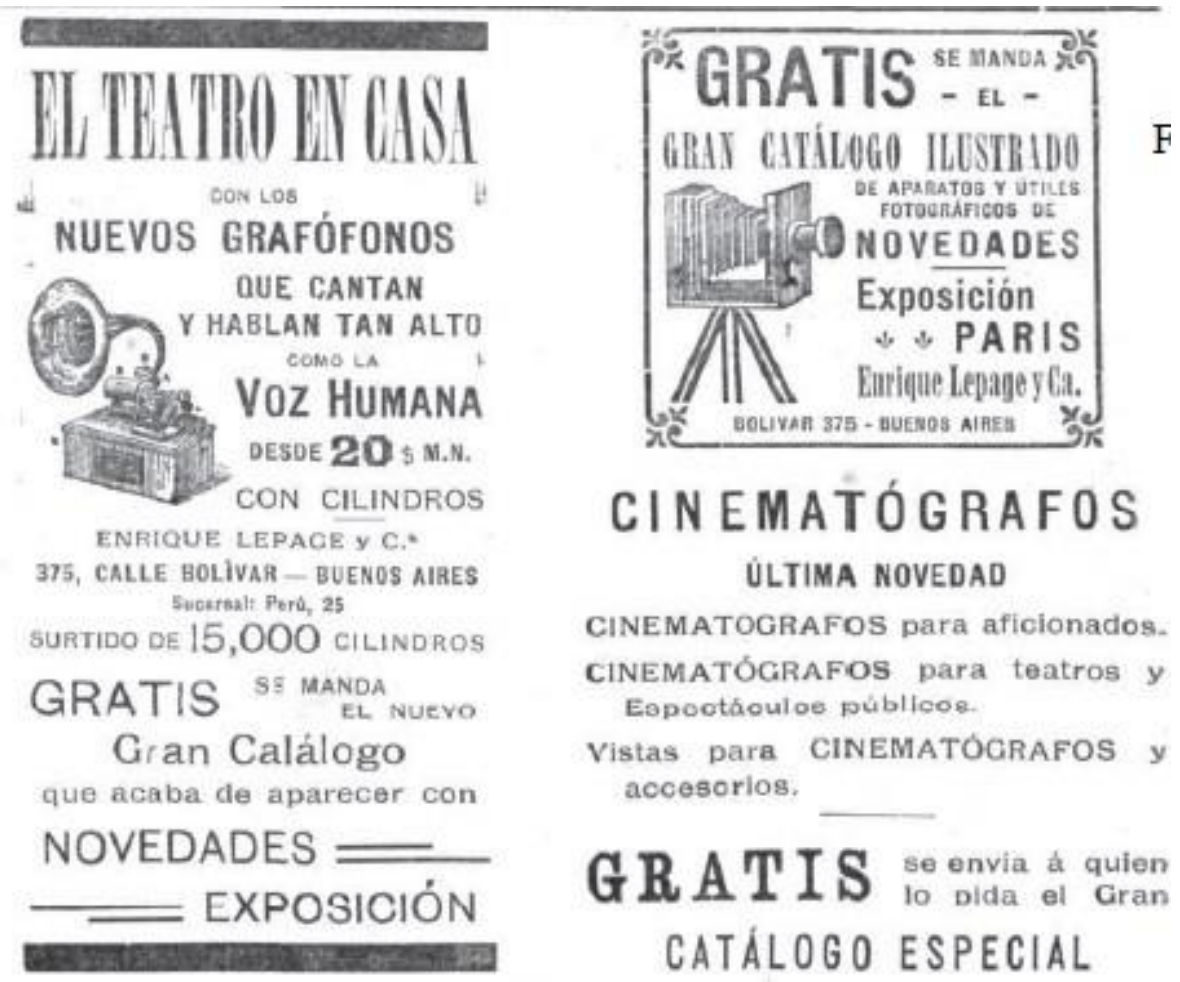

Fonte: Revista Caras y Caretas, N 117, 29 de diciembre de 1900

Con el cambio de año también cambian un poco las imágenes de las publicidades, no solamente aparecerán los precios de los productos, sino que ahora también encontramos los distintos modelos de las cámaras 
fotográficas con sus nombres, como por ejemplo: "El Relámpago", "El Mefisto", "El Rápido", "Apolo", "Rayo", etc. Aparecen al costado de cada cámara una descripción técnica de cuáles son las características del producto y según que placa llevaba era el precio que tenía. Hay una variedad de precios importantes que iban desde $\$ 4.50$ a $\$ 30 \mathrm{~m} / \mathrm{n}$, pasando por intermedios como de $\$ 12.80, \$ 19$ y $\$ 22.90 \mathrm{~m} / \mathrm{n}$.

Con respecto a los productos que reproducen sonido ya apareció en el mercado el disco plano y en el número 144 la casa Cassels planteó una especie de plan canje. Esto esta explicado en el anuncio, "cada docena de discos nuevos que se compre. Se aceptan la devolución hasta doce discos viejos, en buen estado, que se reciben a $\$ 10.00$ la docena. A estos se le estampa el logo de "USADOS" y se venden a $\$ 8.00$ la docena"15. A partir de esto se puede apreciar una cierta circulación de algunos productos que nos hablarían de una cierta cantidad de hogares que tenían un aparato para poder reproducir sonidos, como así también de negocios que contaban con un gramófono. La pregunta podría ser cómo acceder a nuevos discos a un costo accesible, pudiendo desprenderse de otros que ya pasaron de moda o que se cansaron de escuchar.

Cuando arribamos al año 1905 las casas comenzaron a explicitar con que marcas trabajaban, a su vez las marcas también publicitaron la relación de exclusividad con ciertos comercios. Como sucede con los gramófonos marca Monarch y Víctor, más conocidos como "Víctor" que en el número 376 de Caras y Caretas decía que las únicas casas autorizadas para su venta eran la de E. Lapage \& Cía. y Cassels \& Cía.16. En tanto la Casa Tagini trabajaba con los gramófonos Columbia.

Hacia final de ese año la Casa Lapage en el número ya citado anteriormente, 376, utiliza 4 páginas de Caras y Caretas para publicitar todos los productos con los que cuenta. Así en la página 17 y 18 de la publicación mostraba todas sus gamas de cámaras fotográficas, incluyendo el comentario en una de ellas "que este modelo es el preferido de las damas por su pequeño volumen que es más reducido que unos pequeños anteojos". Aquí encontramos que trabajaban ya con la marca Kodak y que ofrecían algunos de sus modelos. También en la página 18 había binoculares o "gemelo" y grafófonos marca Pathé. En

15 Caras y Caretas, № 144, 06 de julio de 1901, p. 05.

16 Caras y Caretas, N 376, 16 de diciembre de 1905, p. 12. Publicidad a página entera. 
la página 19 estaba toda dedicada a los distintos modelos de los gramófonos marca Víctor con la novedad del brazo acústico fijo.

En la página 20 lo que se promocionaba eran dos modelos de cinematógrafos: uno era el cinematógrafo Pathé, donde también aclaraba que eran los únicos concesionarios para las Repúblicas de Argentina y Uruguay, además de mencionar que también contaban con "vistas" para distribuir y un catálogo con el listado de estas. Y el otro cinematógrafo que ofrecían era el Automático, que funciona con una moneda de 10 centavos, produciendo $6 \$$ por hora. El cine de la mano de Glücksmann como gerente de la "Casa Lapage" recorría el país y también Uruguay ${ }^{17}$.

\section{A manera de balance}

El recorrido realizado en estos primeros años de vida de la Casa Lapage y de Glücksmann como su gerente fue muy interesante en relación a distintos problemas.

Al pensar o plantear las diferentes estrategias comerciales que se dio Glücksmann como gerente de Casa Lapage a partir de 1898 hasta lo observado en 1905 tal vez se podría pensar que el mercado se fue construyendo, pero también se podría plantear si ya no existía y lo que se fue creando era el consumidor. En principio ambos planteos no serían excluyentes uno del otro, sino que probablemente ambos se constituyendo en el mismo momento.

Lo que se puede observar en los anuncios de "Caras y Caretas" es que tanto los catálogos como las publicidades rápidamente pasaron a ser centrales en los mecanismos de comercialización de la Casa Lapage. Y cómo, aún en el corto período relevado en este trabajo, se producen cambios cualitativos y cuantitativos dentro del este comercio, ello nos

${ }^{17}$ Caras y Caretas, № 376, 16 de diciembre de 1905, p. 17, 18, 19 y 20. Publicidad a página entera. 
lleva a reflexionar sobre las ideas innovadoras que están en la cabeza de la gerencia del negocio, es decir, de Max Glücksmann.

La masividad y circulación de la Revista Caras y Caretas en principio nos estaría mostrando que importantes sectores de la población conocían estos aparatos. Y si uno evalúa la cantidad de casas que ofrecen cámaras o gramófonos, discos, cilindros, etc., también se podría pensar que hay un amplio sector de la sociedad que puede acceder a estos bienes en una época tan temprana como principio de siglo XX. Queda aún por rastrear cuan amplio es este sector, para esto claramente habría que relevar las ventas, para poder también hacer una evaluación del éxito de los mecanismos de comercialización de la Casa Lapage.

Importante también es marcar la apelación a distintos discursos en las publicidades, es evidente que el negocio tenía un tipo de argumentación para los posibles consumidores hogareños y que en estos primeros años se sostenía a partir de ellos. Pero también se observa cómo va direccionando su guion hacia otro sector de la población, los encargados de los entretenimientos urbanos, aquellos que tenían un teatro, un café, un lugar donde se brindarán espectáculos públicos. Se podría pensar el inicio de estos circuitos de distribución de películas o "vistas", de la venta de máquinas para proyectar películas y la venta o alquiler del material para filmarlas. En la base de esto se encontraba Max Glücksmann como intérprete de lo que estaba pasando con este nuevo espectáculo, el cine.

A partir de todo esto se puede observar estos mecanismo de comercialización ayudaban a una amplia difusión de los productos de este comercio. Que el envío de los catálogos ilustrados de manera gratuita garantizaba, por lo menos en apariencia, el conocimiento de estos nuevos artefactos en toda la ciudad y en los alrededores como así también a otras partes del país y a otros países. Más adelante se sumó a estos circuitos el envió de las "Variedades Max Glücksmann" al exterior para su distribución en Europa.

Los productos, los artefactos, de los que estuvimos hablando eran variados y para que aparecieran fue necesaria una transformación en la técnica. Ellos se trataban de la cámara fotográfica, los fonógrafos, los gramófonos, las cámaras de cine, los productos necesarios para el desarrollo de estos emprendimientos, los accesorios que los acompañaban, etc. 
A partir de esto, la Argentina, como otros países, estuvo muy interesada en estos avances y se mantuvo expectante de los distintos aparatos que iban desarrollándose. Para esto contó con pioneros y gente muy curiosa que tomó riesgos, que se ocupo de generar las relaciones para que estos productos lleguen al país y para que fueran conocidos por todos. Esto en parte está reflejado en el funcionamiento de la Casa Lapage.

Glücksmann sentado en su butaca mirando esa primer cinta animada en 1896 intuyó que allí había una filón para hacerse rico. Soñando cumplir su ilusión, como muchos otros inmigrantes, ayudo a construir o a desarrollar el mercado de entretenimiento en la Argentina. Él fue uno de los que construyó la cultura de masa en la Argentina, la que para la década del 20 estaba asentada en la identidad cine/tango/sainete.

\section{Referências}

BARSKY, J. y BARSKY, O. La Buenos Aires de Gardel. Buenos Aires. Sudamericana. 2008.

BARSKY, J. y BARSKY, O. Gardel. La biografía. Buenos Aires. Taurus. 2004.

CUARTEROLO, A. Representar la Nación: las gestas libertarias en el cine de ficción.

Latinoamericano del período silente. En A. LUSNICH, P. PIEDRAS y S. FLORES (eds.), Cine y revolución en América Latina. Una perspectiva comparada de las cinematografías de la región. Buenos Aires. Imago Mundi. 2014.

CARretero, A. Vida Cotidiana en Buenos Aires 2. Desde la Organización Nacional hasta el Gobierno de Hipólito Yrigoyen (1864-1918). Buenos Aires. Ariel. 2013.

EUJANIAN, A. Historia de Revistas Argentina (1900-1950). La conquista del público. Buenos Aires. Asociación Argentina de Editores de Revistas. 1999.

FERNÁNDEZ RUSSO, M. et. al. Hombre de Suerte: El legado invisible de Max Glücksmann [video]. Universidad de Buenos Aires, Facultad de Arquitectura, Diseño y Urbanismo, Carrera de Diseño de Imagen y Sonido, Diseño Audiovisual II, Cátedra Feller. 2008. En internet disponible en: https://vimeo.com/5104290 
GARCÍA FALCÓ, M. y MÉNDEZ, P. Cinema halls in Buenos Aires a XX century heritage. Recuperado el 13 de octubre de 2014, de http://www.academia.edu/10904081/Cinema_halls_in_Buenos_Aires_ a_XXth_century_heritage.

GONZÁLEZ VELASCO, C. Gente de Teatro. Ocio y espectáculos en la buenos Aires de los años '20. Buenos Aires. Siglo XXI. 2012.

GUTIERREZ, L. y ROMERO L.A. Sectores populares y cultura política. Buenos Aires en la entreguerras. Buenos Aires. Siglo XXI. 2007.

KARUSH, M. Cultura de clase. Radio y Cine en la creación de una Argentina dividida (1920-1946). Buenos Aires. Ariel. 2013.

MARRONE, I. Imágenes del mundo histórico. Identidades y representaciones en el noticiero $\mathbf{y}$ el documental en el cine mudo Argentino. Buenos Aires. Biblos/Archivo General de la Nación. 2003.

PRIAMO, L. Fotografía y vida privada $(1870$ - 1930). En F. DEVOTO y M. MADERO (comp.), Historia de la Vida Privada en la Argentina. La Argentina Plural: 1870 - 1930. Buenos Aires. Taurus. 1999.

PUJOL, S. Valentino en Buenos Aires. Los años '20 y el espectáculo. Buenos Aires. Emecé. 1994.

ROCCHI, F. Inventando la soberanía del consumidor: publicidad, privacidad y revolución del mercado en Argentina, 1860 - 1940. En F. DEVOTO y M. MADERO (comp.), Historia de la Vida Privada en la Argentina. La Argentina Plural: 1870 - 1930. Buenos Aires. Taurus. 1999.

ROCCHI, F. Consumir es un placer. La industria y la expansión de la demanda en Buenos Aires a la vuelta del siglo pasado. Desarrollo Económico, 37 (148), 533-558. 1998.

TRONCOSO, O. Buenos Aires se divierte. Buenos Aires. Centro Editor de América Latina. 1971.

WOLF, S. El periodismo cinematográfico: construcción de los públicos cinematográficos en la década del 20'. Tesis de Licenciatura sin publicar, Universidad de Buenos Aires, 1996. 


\section{Documentos ineditos}

Diario La Prensa, fecha 20 de julio de 1896, la referencia esta sacada de la página 6 de la sección Boletín del día, Novedades Teatrales.

Caras y Caretas. Varios números de los años 1898, 1899, 1900, 1901 y 1905.

Recebido em 24/10/2015

Aceito em 30/12/2015 